\title{
Relationship Between Age-Related Spinopelvic Sagittal Alignment and Low Back Pain in Adults of Population-Based Cohorts: The ROAD Study
}

\author{
Yoshiki Asai' \\ Shunji Tsutsui' \\ Noriko Yoshimura ${ }^{2}$ \\ Hiroshi Hashizume (D) \\ Toshiko lidaka ${ }^{2}$ \\ Chiaki Horii ${ }^{2}$ \\ Hiroshi Kawaguchi ${ }^{3}$ \\ Kozo Nakamura ${ }^{4}$ \\ Sakae Tanaka (iD ${ }^{5}$ \\ Munehito Yoshida' \\ Hiroshi Yamada (D) \\ 'Department of Orthopedic Surgery, \\ Wakayama Medical University, \\ Wakayama, Japan; ${ }^{2}$ Department of \\ Preventive Medicine for Locomotive \\ Organ Disorders, 22nd Century Medical \\ and Research Center, Faculty of \\ Medicine, The University of Tokyo, \\ Tokyo, Japan; ${ }^{3}$ Department of \\ Orthopedic Surgery, Tokyo Neurological \\ Center, Tokyo, Japan; ${ }^{4}$ Department of \\ Orthopedic Surgery, Towa Hospital, \\ Tokyo, Japan; ${ }^{5}$ Department of \\ Orthopedic Surgery, Faculty of Medicine, \\ The University of Tokyo, Tokyo, Japan
}

Correspondence: Shunji Tsutsui Department of Orthopedic Surgery, Wakayama Medical University, 8I I-I Kimiidera, Wakayama, 64I-85I0, Japan Tel +8I-73-44I-0645

Fax +8I-73-448-3008

Email stsutsuil I I6@gmail.com
Purpose: The demand for surgical correction in elderly patients with adult spinal deformity (ASD) has recently increased with the growth of the aging population. Age-related changes in spinopelvic sagittal alignment have been recently reported; thus, sagittal realignment should consider age-related changes. This study aimed to investigate the relationship between age-specific sagittal spinopelvic radiographic parameters and low back pain (LBP) to support the establishment of age-specific realignment targets for patients with ASD.

Materials and Methods: A population-based cohort consisting of 1461 subjects (466 men and 995 women) was used. The participants were divided into five groups based on their age: (1) younger than 50 years, (2) 50-59 years, (3) 60-69 years, (4) 70-79 years, and (5) 80 years and older. Standing lateral whole-spine radiographs were assessed to measure lumbar lordosis (LL), pelvic tilt (PT), pelvic incidence (PI), and sagittal vertical axis (SVA). In addition, all participants were asked if they had LBP or not, using the following question: "Have you experienced LBP on most days during the past month and/or now?".

Results: The crucial parameter associated with LBP was the mismatch between PI and LL (PI-LL). The mean values of all the radiographic parameters increased with age. PI-LL and PT reached $11.5^{\circ}$ and $25.6^{\circ}$, respectively, for women without LBP in the super-aged group (age $>80$ years), which did not lie in the range of optimal values reported in the previous literature.

Conclusion: A new optimal age-related target may be needed for the management of patients with ASD.

Keywords: adult spinal deformity, spinopelvic sagittal alignment, low back pain, population-based cohort

\section{Introduction}

Pain and disability are the most important considerations for the adequate management of patients with adult spinal deformity (ASD). Sagittal plane balance has been demonstrated to be positively associated with pain, physical disability, and reduced quality of life. ${ }^{1,2}$ Thus, its assessment is crucial for ASD treatment. ${ }^{3-6}$ Three $^{-}$ parameters that have been widely used to characterize sagittal alignment in ASD are: 1) regional deformity represented by a mismatch between pelvic incidence (PI) and lumbar lordosis (LL) (PI-LL), 2) compensatory mechanism represented by pelvic tilt (PT), and 3) global alignment measured using the sagittal vertical axis (SVA). ${ }^{5,6}$ Among these parameters, PI-LL has emerged as a key parameter since Schwab et al proposed the formula $\left(\mathrm{LL}=\mathrm{PI} \pm 9^{\circ}\right)$ to estimate the optimal sagittal 
alignment required after spinal fusion surgery for ASD treatment in patients with a mean age of 57 years. $^{3-5}$ However, the demand for surgical correction for elderly patients (aged 65 years or older) with ASD has recently increased with the growth of the aging population. In our previous study, age-related normative values of spinopelvic sagittal alignment in adults were demonstrated using population-based cohorts. ${ }^{7}$ Sagittal realignment should also consider age-related changes. ${ }^{6,8}$ In the present study, the relationship between age-specific values for sagittal spinopelvic parameters and low back pain (LBP) was investigated to support the establishment of age-specific realignment targets for patients with ASD.

\section{Materials and Methods}

This study was conducted in accordance with the Declaration of Helsinki, and the study design was approved by the Ethics Committee of the University of Tokyo.

With the approval of our institutional review board, the Research on Osteoarthritis/Osteoporosis Against Disability (ROAD) study was initiated as a nationwide, prospective study of bone and joint diseases in population-based cohorts. A detailed profile of the ROAD cohort was previously reported. ${ }^{9,10}$ In brief, participants of the third visit of the ROAD study conducted from 2012 to 2013 were recruited. In addition to the former participants, inhabitants of the mountainous and coastal areas in the Wakayama prefecture willing to participate in the ROAD survey were also included in the third visit. Overall, 1575 individuals (513 men and 1062 women) participated in the third visit of the ROAD study. Of the 1575 participants, 114 individuals, for whom standing lateral whole-spine radiographs were not obtained or whose radiographs were not available for evaluation were excluded. Finally, 1461 participants (466 men and 995 women) were included in this study. The participants were divided into five groups based on their age: (1) younger than 50 years, (2) 50-59 years, (3) 60-69 years, (4) 70-79 years, and (5) 80 years and older. All individuals provided written informed consent.

For each subject, a standing lateral radiograph of the whole spine and pelvis was obtained using a 40 -inch film. Each radiograph was aligned so that the edge of the film was used as a reference for vertical alignment. As described previously, ${ }^{11}$ the participants were instructed to stand in a comfortable position, with their hips and knees fully extended. The arms were flexed with hands resting on shoulder-level supports. On the radiographs, the following parameters were measured: LL $\left(^{\circ}\right.$ ) (the Cobb angle from the upper endplate of L1 to the lower endplate of S1), PT $\left(^{\circ}\right.$ ) (the angle between the line connecting the midpoint of the sacral plate to the axis of the femoral heads and the vertical axis), PI $\left(^{\circ}\right)$ (the angle between the line perpendicular to the sacral plate at its midpoint and the line connecting this point to the axis of the femoral heads), and SVA $(\mathrm{mm})$ (the horizontal distance from the $\mathrm{C} 7$ plumb line originating at the middle of the $\mathrm{C} 7$ vertebral body to the posterior superior endplate of S1) (Figure 1). In addition, experienced board-certified orthopedic surgeons interviewed all the participants regarding their symptoms. The
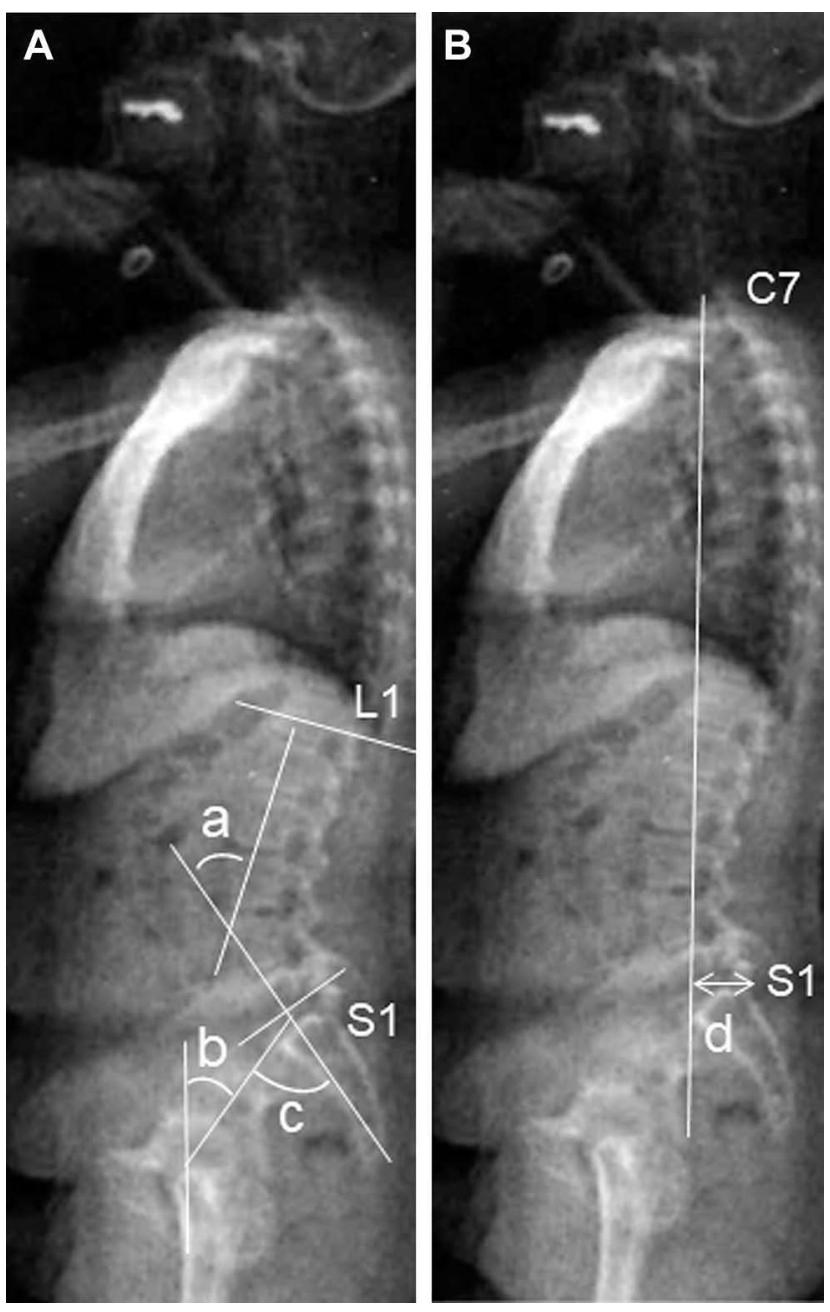

Figure I Parameters measured on lateral radiographs of the whole spine and pelvis (A) angular parameters $\left({ }^{\circ}\right)$; a) lumbar lordosis; the Cobb angle from the upper endplate of $\mathrm{LI}$ to the lower endplate of SI, b) pelvic tilt, the angle between the line connecting the midpoint of the sacral plate to the axis of the femoral heads and the vertical axis; c) pelvic incidence; the angle between the line perpendicular to the sacral plate at its midpoint and the line connecting this point to the axis of the femoral heads. (B) Linear parameter $(\mathrm{mm})$; d) sagittal vertical axis; horizontal distance from the $\mathrm{C7}$ plumb line originating at the middle of the $\mathrm{C7}$ vertebral body to the posterior superior endplate of SI. 
following question was used to assess the presence of LBP: "Have you experienced LBP on most days during the past month and/or now?" Those who answered "yes" were defined as having LBP based on previous studies. $^{12-17}$

Chi-square tests were used to analyze the categorical data, whereas Student's $t$-tests were used to compare the radiographic parameters between subjects with LBP and those without LBP in each age group. Statistical analyses were performed using JMP version 8 (SAS Institute Inc., Cary, NC, USA). $\mathrm{P}<0.05$ was considered statistically significant.

\section{Results}

An overview of the participants' characteristics $(n=1461)$ is presented in Table 1. According to the World Health Organization classification, ${ }^{18}$ the mean body mass index was within the normal range (18.5-24.9) in all the groups except for males in group 1. The prevalence of LBP was approximately $40 \%$ in each group, also when the groups were stratified based on sex. There were no statistically significant differences observed in the prevalence among the groups in both men and women and between men and women (Table 2).

According to the radiographic examination shown in Table 3, all values of PI-LL, PT, and SVA increased with age in both men and women and were greater in participants with LBP than in those without LBP. The most significant radiographic parameter associated with the presence of LBP was the PI-LL. A significant difference in PI-LL values was observed between patients with and without LBP in most of the patients aged over 50 years. Interestingly, the mean value of PI-LL in women without LBP aged over 80 years was $11.5^{\circ}$, which exceeds the previously described normative value of PI-LL $\left(<10^{\circ}\right)$.

\section{Discussion}

Based on the present study using an overall healthy population-based cohort, the crucial radiographic parameter

Table I Anthropometric Characteristics of the Participants

\begin{tabular}{|c|c|c|c|c|}
\hline \multicolumn{5}{|c|}{ Male } \\
\hline & No. of Participants & Height (cm) & Weight (kg) & BMI $\left(\mathrm{kg} / \mathrm{m}^{2}\right)$ \\
\hline Total & 466 & $164.7 \pm 7.3$ & $64.2 \pm 11.4$ & $23.6 \pm 3.4$ \\
\hline \multicolumn{5}{|c|}{ Age strata (years) } \\
\hline$\leq 49$ & 56 & $171.3 \pm 6.8$ & $73.4 \pm 11.8$ & $25.1 \pm 5.0$ \\
\hline $50-59$ & 75 & $168.3 \pm 6.3$ & $68.7 \pm 11.9$ & $24.2 \pm 3.4$ \\
\hline $60-69$ & 124 & $166.3 \pm 5.4$ & $65.9 \pm 9.4$ & $23.8 \pm 3.2$ \\
\hline 70-79 & 123 & $162.7 \pm 6.1$ & $62.2 \pm 9.5$ & $23.5 \pm 2.9$ \\
\hline$\geq 80$ & 88 & $158.1 \pm 5.9$ & $55.1 \pm 8.4$ & $22.0 \pm 2.9$ \\
\hline \multicolumn{5}{|c|}{ Female } \\
\hline & No. of Participants & Height (cm) & Weight (kg) & BMI $\left(\mathrm{kg} / \mathrm{m}^{2}\right)$ \\
\hline Total & 995 & $|5| .8 \pm 6.7$ & $52.4 \pm 8.7$ & $22.7 \pm 3.5$ \\
\hline \multicolumn{5}{|c|}{ Age strata (years) } \\
\hline$\leq 49$ & 114 & $158.3 \pm 4.7$ & $54.2 \pm 8.7$ & $21.6 \pm 3.2$ \\
\hline $50-59$ & 181 & $155.3 \pm 4.7$ & $55.6 \pm 9.4$ & $23.1 \pm 4.2$ \\
\hline $60-69$ & 294 & $152.3 \pm 5.7$ & $52.6 \pm 8.2$ & $22.7 \pm 3.3$ \\
\hline 70-79 & 284 & $149.3 \pm 5.9$ & $51.9 \pm 7.7$ & $23.3 \pm 3.3$ \\
\hline$\geq 80$ & 122 & $145.2 \pm 5.8$ & $46.7 \pm 7.8$ & $22.1 \pm 3.4$ \\
\hline
\end{tabular}

Note: Values are presented as mean \pm standard deviation.

Abbreviation: BMl, body mass index. 
Table 2 Prevalence of Low Back Pain

\begin{tabular}{|l|c|c|c|c|}
\hline Age Strata (Years) & Overall & Male & Female & $\mathbf{p}^{*}$ \\
\hline$\leq 49$ & $66 / 170(38.8 \%)$ & $18 / 56(32.1 \%)$ & $48 / 114(42.1 \%)$ & 0.210 \\
\hline $50-59$ & $109 / 256(42.6 \%)$ & $29 / 75(38.7 \%)$ & $80 / 181(44.2 \%)$ & 0.415 \\
\hline $60-69$ & $163 / 418(39.0 \%)$ & $54 / 124(43.5 \%)$ & $109 / 294(37.1 \%)$ & 0.215 \\
\hline $70-79$ & $173 / 407(42.5 \%)$ & $54 / 123(43.9 \%)$ & $119 / 284(41.9 \%)$ & 0.708 \\
\hline$\geq 80$ & $93 / 210(44.3 \%)$ & $34 / 88(38.6 \%)$ & $59 / 122(48.4 \%)$ & 0.163 \\
\hline$P^{*}$ & 0.638 & 0.571 & 0.259 & \\
\hline
\end{tabular}

Notes: Values are presented as number (percentage). ${ }^{*}$ Chi-square test.

Abbreviations: BMI, body mass index; LBP, low back pain.

associated with LBP in spinopelvic sagittal alignment was PI-LL. Furthermore, the mean values of PI-LL and PT in patients without LBP increased with age and reached $11.5^{\circ}$ and $25.6^{\circ}$, respectively, particularly for women in the super-aged group (older than 80 years). In Scoliosis Research Society-Schwab ASD classification, PI-LL < $10^{\circ}$, $\mathrm{PT}<20^{\circ}$, and SVA $<4 \mathrm{~cm}$ have recently been determined as the ideal goals in the management of ASD. ${ }^{5}$ This well recognized formula developed by Schwab et al was based on the investigation of healthrelated quality-of-life measures in ASD patients with the mean age of 57 years. ${ }^{5}$ Nonetheless, the findings of the present study suggest that the optimal goal for the management of ASD should account for age, and PI-LL $>10^{\circ}$ could be accepted for elderly patients. Recently, some researchers have reported a formula including age for the treatment of ASD., ${ }^{8,19}$ In addition, Schwab et al also demonstrated that the targets of operative realignment should account for age. ${ }^{6}$ Furthermore, ethnic variations between health-related quality-of-life measures and radiographic parameters in the setting of ASD have also been reported, suggesting the need for population-adjusted sagittal modifiers in the management of ASD. ${ }^{20}$

However, age-adjusted alignment goals based on PILL, PT, and SVA have yet to yield definitive guidelines for ASD surgery due to high rates of mechanical complications. ${ }^{21}$ Moreover, it has been recently reported that restoring the individual normal sagittal shape of the

Table 3 Comparison of Spino-Pelvic Parameters Between Subjects with and without Low Back Pain in Each Age Stratum

\begin{tabular}{|c|c|c|c|c|c|c|c|c|c|c|}
\hline \multirow[b]{2}{*}{ Age Strata (Years) } & \multirow[b]{2}{*}{ Sex } & \multicolumn{3}{|c|}{ PI-LL $\left({ }^{\circ}\right)$} & \multicolumn{3}{|c|}{ PT $\left({ }^{\circ}\right)$} & \multicolumn{3}{|c|}{ SVA (mm) } \\
\hline & & LBP (-) & LBP (+) & *p & LBP (-) & LBP (+) & *p & LBP (-) & LBP (+) & *p \\
\hline \multirow[t]{2}{*}{$\leq 49$} & M & $-2 . I \pm 6.1$ & $-0.6 \pm 10.8$ & 0.4898 & $10.9 \pm 5.7$ & $13.2 \pm 8.8$ & 0.2340 & $-11.7 \pm 19.9$ & $-9.2 \pm 29.3$ & 0.7106 \\
\hline & $\mathrm{F}$ & $-1.0 \pm 8.9$ & $-1.0 \pm 9.2$ & 0.9932 & $14.2 \pm 6.5$ & $14.8 \pm 6.9$ & 0.6461 & $-18.8 \pm 24.9$ & $-18.7 \pm 24.6$ & 0.9856 \\
\hline \multirow[t]{2}{*}{$50-59$} & $M$ & $0.1 \pm 8.8$ & $5.4 \pm 12.5$ & 0.0200 & $13.4 \pm 6.6$ & $15.0 \pm 6.6$ & 0.3019 & $2.9 \pm 30.9$ & $8.3 \pm 31.1$ & 0.4745 \\
\hline & $\mathrm{F}$ & $-I . I \pm 9.8$ & $3.7 \pm 12.5$ & 0.0035 & $14.3 \pm 7.5$ & $17.9 \pm 8.0$ & 0.0018 & $-11.4 \pm 23.8$ & $-3.3 \pm 27.4$ & 0.0359 \\
\hline \multirow[t]{2}{*}{$60-69$} & M & $1.0 \pm 9.7$ & $4.8 \pm 9.7$ & 0.0262 & $14.3 \pm 7.1$ & $16.0 \pm 6.8$ & 0.1586 & $4.2 \pm 27.7$ & $13.3 \pm 42.0$ & 0.1495 \\
\hline & $\mathrm{F}$ & $2.7 \pm 11.7$ & $5.1 \pm 13.7$ & 0.1076 & $17.5 \pm 8.4$ & $18.8 \pm 8.5$ & 0.2239 & $0.8 \pm 29.9$ & $4.0 \pm 37.2$ & 0.4116 \\
\hline \multirow[t]{2}{*}{ 70-79 } & M & $0.1 \pm 9.7$ & $4.3 \pm 14.7$ & 0.0483 & $15.0 \pm 6.6$ & $17.5 \pm 8.5$ & 0.0534 & $10.0 \pm 32.8$ & $19.8 \pm 47.1$ & 0.1787 \\
\hline & $\mathrm{F}$ & $6.3 \pm \mid 4.1$ & $13.6 \pm 14.7$ & $<0.0001$ & $21.5 \pm 10.3$ & $25.5 \pm 10.0$ & 0.0010 & $17.3 \pm 42.4$ & $33.9 \pm 42.4$ & 0.0014 \\
\hline \multirow[t]{2}{*}{$\geq 180$} & M & $6.9 \pm 13.2$ & $14.8 \pm 19.2$ & 0.0207 & $19.1 \pm 8.2$ & $22.1 \pm 9.9$ & 0.1174 & $33.3 \pm 51.1$ & $49.8 \pm 60.3$ & 0.1840 \\
\hline & $F$ & $11.5 \pm 14.0$ & $|5.9 \pm 21|$. & 0.1608 & $25.6 \pm 10.1$ & $25.2 \pm 10.8$ & 0.8296 & $37.9 \pm 54.7$ & $67.0 \pm 57.5$ & 0.0048 \\
\hline
\end{tabular}

Notes: Values are presented as mean \pm standard deviation. *Student's $t$-test. Bold values are statistically significant.

Abbreviations: PI, pelvic incidence; LL, lumbar lordosis; PT, pelvic tilt; SVA, sagittal vertical axis; LBP, low back pain; M, male; F, female. 
spine based on PI according to the Roussously classification resulted in reducing the potential risk of mechanical complications. $^{22,23}$ Further studies on the sagittal shape using our cohort may lead to proposing better guidelines for the management of ASD.

The present study has several limitations. First, this was a cross-sectional study; thus, the natural history of spinopelvic sagittal alignment or causal relationship between agerelated changes in spinopelvic sagittal alignment and LBP could not be identified. Second, although the ROAD study included a large number of subjects, regional selection bias should be considered. ${ }^{24}$ The participants were recruited from a limited area of the country, suggesting a possibility that the study population may not represent the general population. Third, the definition of LBP is different in various studies. ${ }^{12}$ In our cohort study, patient-reported outcome measurements related to the disability resulting from low back pain, such as Oswestry Disability Index, were not included. LBP was evaluated using just one questionnaire, "LBP present on most days during the past month and/or now," which might have led to measurement bias. However, several previous studies have elucidated the relationship between radiographic findings and low back pain using the cohort and low back pain questionnaire same as the one in this study. ${ }^{13-17}$ Therefore, we believe that the effectiveness of this low back pain questionnaire in scientific reports has already been proven. Fourth, LBP has been recognized as a multifactorial symptom. Although anthropometric data (height, weight, and body mass index), which may be associated with $\mathrm{LBP}^{25}$ were analyzed, activities in daily life, psychological status, and various anatomical components of the spine, including intervertebral discs, facet joints, and paraspinal muscles, were not investigated in this study.

However, to the best of our knowledge, we have investigated the largest cohort with a wide range of ages compared to previous studies. The findings of this study may provide important information to help improve the treatment of elderly patients with ASD.

\section{Conclusion}

The radiographic values of spinopelvic sagittal alignment, consisting of PI-LL, PT, and SVA, increased with age, and PI-LL emerged as a crucial parameter associated with LBP. In addition, radiographic values established as non-optimal in the previous literature ${ }^{5}$ were observed even in elderly individuals without LBP. A new optimal formula may be needed for the management of elderly patients with ASD.

\section{Disclosure}

The authors report no conflicts of interest in this work.

\section{References}

1. Glassman SD, Berven S, Bridwell K, Horton W, Dimar JR. Correlation of radiographic parameters and clinical symptoms in adult scoliosis. Spine (Phila Pa 1976). 2005;30(6):682-688. doi:10.1097/01.brs.0000155425.04536.f7

2. Glassman SD, Bridwell K, Dimar JR, Horton W, Berven S, Schwab F. The impact of positive sagittal balance in adult spinal deformity. Spine (Phila Pa 1976). 2005;30(18):2024-2029. doi:10.1097/01.brs.0000179086.30449.96

3. Schwab F, Lafage V, Patel A, Farcy JP. Sagittal plane considerations and the pelvis in the adult patient. Spine (Phila Pa 1976). 2009;34 (17):1828-1833. doi:10.1097/BRS.0b013e3181a13c08

4. Lafage V, Schwab F, Patel A, Hawkinson N, Farcy JP. Pelvic tilt and truncal inclination: two key radiographic parameters in the setting of adults with spinal deformity. Spine (Phila Pa 1976). 2009;34(17): E599-606. doi:10.1097/BRS.0b013e3181aad219

5. Schwab F, Ungar B, Blondel B, et al. Scoliosis Research Society-Schwab adult spinal deformity classification: a validation study. Spine (Phila Pa 1976). 2012;37(12):1077-1082. doi:10.1097/ BRS.0b013e31823e15e2

6. Lafage R, Schwab F, Challier V, et al. Defining spino-pelvic alignment thresholds: should operative goals in adult spinal deformity surgery account for age? Spine (Phila Pa 1976). 2016;41(1):62-68. doi:10.1097/BRS.0000000000001171

7. Asai $\mathrm{Y}$, Tsutsui $\mathrm{S}$, Oka H, et al. Sagittal spino-pelvic alignment in adults: the Wakayama Spine Study. PLoS One. 2017;12(6):e0178697. doi:10.1371/journal.pone.0178697

8. Xu L, Qin X, Zhang W, et al. Estimation of the ideal lumbar lordosis to be restored from spinal fusion surgery: a predictive formula for Chinese population. Spine (Phila Pa 1976). 2015;40(13):1001-1005. doi:10.1097/BRS.0000000000000871

9. Yoshimura N, Oka H, Muraki S, et al. Reference values for hand grip strength, muscle mass, walking time, and one-leg standing time as indices for locomotive syndrome and associated disability: the second survey of the ROAD study. J Orthopaed Sci. 2011;16(6):768-777. doi:10.1007/s00776-011-0160-1

10. Yoshimura N, Muraki S, Oka H, et al. Mutual associations among musculoskeletal diseases and metabolic syndrome components: a 3-year follow-up of the ROAD study. Modern Rheumatol. 2015;25 (3):438-448. doi:10.3109/14397595.2014.972607

11. Zhu Z, Xu L, Zhu F, et al. Sagittal alignment of spine and pelvis in asymptomatic adults: norms in Chinese populations. Spine (Phila Pa 1976). 2014;39(1):E1-6. doi:10.1097/BRS.0000000000 000022

12. Dionne CE, Dunn KM, Croft PR, et al. A consensus approach toward the standardization of back pain definitions for use in prevalence studies. Spine (Phila Pa 1976). 2008;33(1):95-103. doi:10.1097/ BRS.0b013e31815e7f94

13. Muraki S, Oka H, Akune T, et al. Prevalence of radiographic lumbar spondylosis and its association with low back pain in elderly subjects of population-based cohorts: the ROAD study. Ann Rheum Dis. 2009;68(9):1401-1406. doi:10.1136/ard.2007.087296

14. Muraki S, Akune T, Oka H, et al. Impact of knee and low back pain on health-related quality of life in Japanese women: the Research on Osteoarthritis against Disability (ROAD). Mod Rheumatol. 2010;20 (5):444-451. doi:10.1007/s10165-010-0307-5

15. Teraguchi M, Yoshimura N, Hashizume H, et al. The association of combination of disc degeneration, end plate signal change, and Schmorl node with low back pain in a large population study: the Wakayama Spine Study. Spine J. 2015;15(4):622-628. doi:10.1016/j. spinee.2014.11.012 
16. Sasaki T, Yoshimura N, Hashizume H, et al. MRI-defined paraspinal muscle morphology in Japanese population: the Wakayama spine study. PLoS One. 2017;12(11):e0187765. doi:10.1371/journal.pone.0187765

17. Shinto K, Minamide A, Hashizume H, et al. Prevalence of facet effusion and its relationship with lumbar spondylolisthesis and low back pain: the Wakayama Spine Study. $J$ Pain Res. 2019;12:3521-3528. doi:10.2147/JPR.S227153

18. WHO. Obesity: preventing and managing the global epidemic. World Health Organ Tech Rep Ser. 2000;894:252.

19. Hasegawa K, Okamoto M, Hatsushikano S, Shimoda H, Ono M, Watanabe K. Normative values of spino-pelvic sagittal alignment, balance, age, and health-related quality of life in a cohort of healthy adult subjects. Eur Spine J. 2016;25(11):3675-3686. doi:10.1007/ s00586-016-4702-2

20. Ames C, Gammal I, Matsumoto M, et al. Geographic and ethnic variations in radiographic disability thresholds: analysis of North American and Japanese operative adult spinal deformity populations. Neurosurgery. 2016;78(6):793-801. doi:10.1227/ NEU.0000000000001184
21. Sebaaly A, Gehrchen M, Silvestre C, et al. Mechanical complications in adult spinal deformity and the effect of restoring the spinal shapes according to the Roussouly classification: a multicentric study. Eur Spine J. 2020;29(4):904-913. doi:10.1007/s00586-019-06253-1

22. Sebaaly A, Grobost P, Mallam L, Roussouly P. Description of the sagittal alignment of the degenerative human spine. Eur Spine J. 2018;27(2):489-496. doi:10.1007/s00586-017-5404-0

23. Sebaaly A, Riouallon G, Obeid I, et al. Proximal junctional kyphosis in adult scoliosis: comparison of four radiological predictor models. Eur Spine J. 2018;27(3):613-621. doi:10.1007/s00586-017-5172-x

24. Yoshimura N, Muraki S, Oka H, Kawaguchi H, Nakamura K, Akune T. Cohort profile: research on osteoarthritis/osteoporosis against disability study. Int J Epidemiol. 2010;39(4):988-995. doi:10.1093/ije/dyp276

25. Su CA, Kusin DJ, Li SQ, Ahn UM, Ahn NU. The association between body mass index and the prevalence, severity, and frequency of low back pain: data From the Osteoarthritis Initiative. Spine (Phila Pa 1976). 2018;43(12):848-852. doi:10.1097/BRS.0000000000002601

\section{Publish your work in this journal}

The Journal of Pain Research is an international, peer reviewed, open access, online journal that welcomes laboratory and clinical findings in the fields of pain research and the prevention and management of pain. Original research, reviews, symposium reports, hypothesis formation and commentaries are all considered for publication. The manuscript management system is completely online and includes a very quick and fair peer-review system, which is all easy to use. Visit http:// www.dovepress.com/testimonials.php to read real quotes from published authors. 